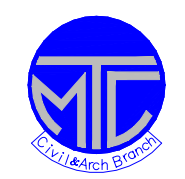

\title{
ICCAE
}

Military Technical College

Kobry Elkobbah, Cairo, Egypt 6th International Conference

on Civil \& Architecture

Engineering

\section{MITIGATION OF POUNDING BETWEEN ADJACENT BUILDINGS USING VISCO-ELASTIC DAMPERS}

\author{
Fayed M. ${ }^{1}$, Mourad S. ${ }^{2}$, Embabay A. ${ }^{3} \&$ Ahmed O. ${ }^{4}$
}

\section{ABSTRACT}

In recent decades, due to the available land resources in modern cities are limited; the buildings are being constructed close to each other (adjacent buildings). In most cases the separation distances between such buildings may be not sufficient to prevent any pounding effects that can occur during an earthquake event. The objective of this study is to investigate the minimum required separation distance which may mitigate or prevent the effects of pounding for new constructed buildings. The pounding effects may also be reduced in case of existing adjacent buildings with insufficient separation distances by placing a mechanical damper with a proper damping coefficient between such buildings. The effectiveness of such mechanical damper was investigated through a parametric study for different separation distances between buildings. Linear dynamic time-history analysis was conducted for the studied cases under the action of three different artificial earthquakes. The efficient value of damping coefficient of the damper was investigated for the studied cases to mitigate pounding effects. The resulted separation distances that prevent the occurrence of pounding were compared with those listed in different international codes.

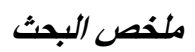

شهدت العقود الحيثة بناء مباني متلاصقة ببعضها البعض كنتيجة لعدم توفر الأراضي في المدن الحيثة اللازمة لبناء

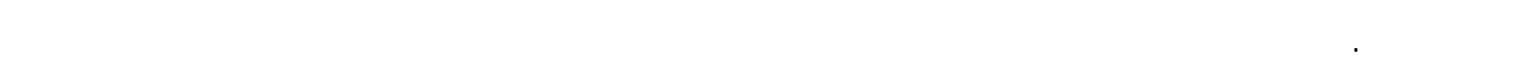

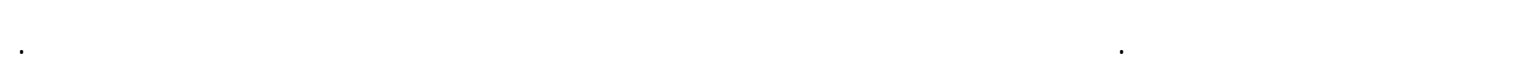

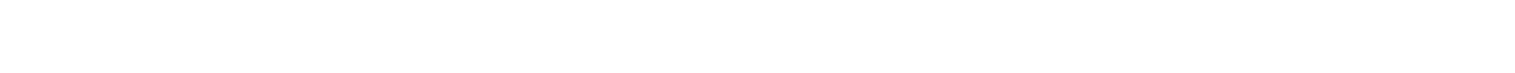

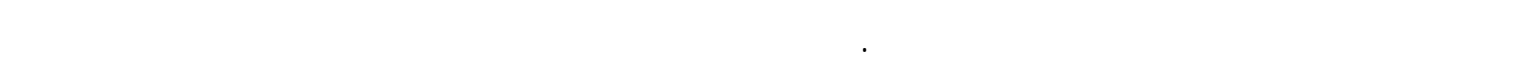

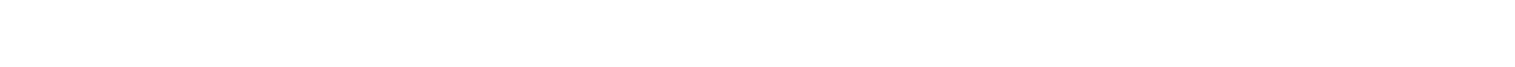

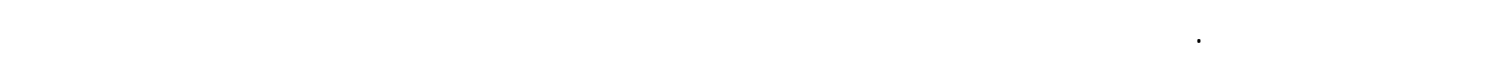
بالأكواد العالمية المختلفة.

\section{2- INTRODUCTION}

During an earthquake, adjacent buildings with insufficient separation distances often collide into each other. This "collisions" or "seismic pounding" imposes unexpected impact forces on buildings causing sever damage that can produce in some cases total collapse. The earthquake 
that struck Mexico City in 1985 reveled that pounding was present in over $40 \%$ of the 330 collapsed or severally damaged buildings surveyed, and in $15 \%$ of all cases, it led to collapse (Emilio

R. and Robert, M., 1986). Many researches addressed the problem of pounding from different points of view. Angagnostopoulos, S.A, K. V., 1990 \& Maiso, B. F., and Kasai, K., 1990 \& Embaby, A., 2000, used different approaches to investigate the effect of pounding of adjacent buildings on the dynamic response under different earthquake records for buildings with different relative dynamic characteristics and different separation distances. Filiatrault, A. and Cervantes, M., 1995, investigated the required separation between buildings in order to avoid the pounding effects.

Other researches attempt to develop different devices to connect existing adjacent buildings in order to mitigate the pounding effects. Kobori et al., 1988 developed bell-shaped hollow connectors to link adjacent buildings in a complex. The bell-shaped hollow connector is made of steel with stabilized hysteretic characteristic when the connector yields so that it can absorb vibration energy of the buildings during a strong earthquake. However, the appropriate yield strength of the connector need to be determined because if the yield strength is too high, the connector may not function properly but if the yield strength is too low, the energy absorbing capacity may be too small during a strong earthquake.

The effect of introducing damping devices with different damping coefficient to connect adjacent multi-storey buildings under earthquake excitation was presented by $\mathrm{Xu}, \mathrm{Y}$. et al. 1999, Embaby. A, Mourad, S., 2000, the results indicated that dampers have significant effect in reducing the shear forces of the buildings.

The objective of this study is to mitigate the effects of pounding between adjacent buildings when subjected to seismic loads. Mitigation of pounding can be achieved either by providing the required separation distance between new constructed buildings or by placing visco-elastic damper between existing adjacent buildings. The behavior of pounding between buildings was investigated for different separation distances and with different damping coefficients, through a linear dynamic time-history analysis under the action of three moderate artificial earthquakes. The efficient value of damping coefficient of the dampers that contributes in mitigating or preventing the pounding, is studied in this research. The resulted separation distances that prevent pounding effects were compared with those specified by the different international codes to examine its conservatism.

\section{3- DAMPER CONFIGURATION AND DAMPING MECHANISM}

In general, the visco-elastic dampers are used to dissipate the generated energy in the buildings due to the seismic excitation. In recent years, the dampers have been successfully incorporated in a number of tall buildings as a viable energy dissipating system (such as shock absorber bracing systems) to suppress wind and earthquake induced motion of building structures. The effectiveness of visco-elastic dampers has been demonstrated experimentally and analytically by many researches over the past 25 years. In seismic applications, the visco-elastic dampers can be incorporated either into new constructions or as a viable tool for the retrofit of existing buildings.

A method of employing a visco-elastic material as a damping medium was introduced by Samali . B, and Kwok. K, 1995. In such a damper the energy is dissipated by extensional deformation of the visco-elastic layer that is connected to the vibrating parts such as plates and beams, as shown in Fig.1. In Other types of dampers, the damping coefficient can be adjusted by regulating the valves opening of the oil flow, such type have been developed and 
tested by Kawshima 1992. In common practice the damper does not need to be installed within the small separation distance between the frames, but it can be connected to the two frames of the two buildings and installed inside the space of one of the frames near the ceiling or the floor. Therefore in this research such types of dampers can be used to connect the adjacent building models.

\section{4- GENERAL EQUATION OF MOTION (DYNAMIC BEHAVIOR OF STRUCTURES)}

Let building 1 and building 2 have $\mathrm{n}+\mathrm{m}$ stories and $\mathrm{n}$ stories, respectively, as shown in Fig .2. The mass and shear stiffness for the $i^{\text {th }}$ story are $m_{i 1}, K_{i 1}$ for building 1 and $m_{i 2}, K_{i 2}$ for building 2 . The damping coefficient of the damper at the $\mathrm{n}$ floor is $c d_{n}$ and the stiffness coefficient of the gap element is $K d_{n}$. The dual-structure dynamic model is taken to be $2 n+m$ degree of freedom system (Xu. Y et. al, 1997), hence the equations of motion of the system can be put in the following matrices form:

$$
[M] \ddot{Y}+[C] \dot{Y}+[K] Y=-[M] \ddot{Y}_{g}
$$

Where; $[\mathrm{M}]$ is the mass matrices of the whole system. [C] is the damping matrix including the damper damping coefficient, and $[\mathrm{K}]$ is the global stiffness matrices of the system including the stiffness of the gap element between both buildings, and can be presented as follows;

$$
\begin{aligned}
{[M] } & =\left[\begin{array}{cc}
m_{n+m, n+m} & 0_{n+m, n} \\
0_{n, n+m} & m_{n n}
\end{array}\right] \\
{[C] } & =\left[C_{i}\right]+\left[C_{d}\right] \\
{[K] } & =\left[K_{b}\right]+\left[K_{g a p}\right]
\end{aligned}
$$

Where; $m_{n+m, n+m}$ and $m_{n, n}$ are the mass matrices of building 1 and building 2 respectively, and $\left[C_{i}\right]$ is the inherent damping matrices of both buildings; $\left[C_{d}\right]$ is the additional damping matrices of the installed damper, $\left[K_{b}\right]$ is the global stiffness matrices of the adjacent buildings, and $\left[K_{g a p}\right]$ is the additional stiffness matrices due to the installation of the fluid damper, $\ddot{Y}_{g}$ is the applied acceleration at the foundation of the building. $\mathrm{Y}$ is the relative displacement vector with respect to the ground for and building 1 and building 2, and given as follows; The details of each matrix are listed as follows:

$$
Y^{T}=\left[y_{11}, y_{21}, \ldots, y_{n+m-1,1}, y_{n+m, 1}, y_{12}, y_{22}, \ldots ., y_{n-1,2}, y_{n 2}\right]
$$


For the time domain analysis, the above equations can be used directly for any given time history record of ground motion. Cosmos/M (1993) finite element package was utilized through out the present study to solve the dynamic equilibrium equations

\section{PARAMETRIC STUDY}

\subsection{Mathematical models}

Generally adjacent buildings can have different structural systems with different layouts and parameters, because of the complexity of the pounding behavior that depends on several parameters, a simple adjacent building model was assumed in this study. The adjacent building models were assumed to be consisted of typical frames spaced equally by $6 \mathrm{~m}$ for both adjacent buildings with all floors aligned at the same level. Hence only a typical frame from each building was considered in the study.

Two models of pounding were used in the parametric study; the first model was a ten storey frame that was constructed closely to a five storey frame with different separation distance. The second model was represented by replacing the ten-storey frame in first model by a fifteen storey frame. The general layout of the two pounding models is illustrated in Fig. 3. All frame members used in both models were designed according to the Egyptian Code for Design and Construction of Concrete Structures, 2001, under the action of loads given by the Egyptian Code for Calculation of Loads and Forces in Structural and Masonry Works. The resulted dimensions of all frame members used in this study are given in Table 1.

Both models incorporates rigid beam-column connections, with all column fixed at base, since the models were subjected to moderate earthquakes, all frame members were assumed to behave linearly elastic. Floor masses were assumed to be lumped and distributed at the beamcolumn joints of each floor and to be acting in the horizontal direction. However the lumped masses were changed in the parametric study to produce different dynamic characteristic of the frames. Such change of masses can be resulted from changing the spacing between frames in the longitudinal direction of the building and/or considering different dead and live loads in each building. Five different cases of total masses were considered for the 5-storey frame, while three different cases of total masses were considered for the 10-storey frame and only one case of total masses was considered for the 15-storey frame. The values of the different masses and the periods of the first five vibration modes for the 5, 10 and 15 storey frames are given in Table 2.

However, a survey of the actual pounding incidents shows that the damage is typically concentrated at the roof level of the shorter building (Maiso. B, Kasai. K, 1992). This suggests that the major impact force typically occurs at the roof level, and that a single-contact-point assumption may be reasonable approximation to the actual condition (Maiso. B, Kasai. K, 1992 \& Embaby. A, Mourad. S, 2000). Accordingly, in this study the interaction between the adjacent buildings is accounted for by using an elastic gap element connecting the two buildings at the top level of the lower building. This element introduces a linear elastic compressive spring, which transmits forces due to building collision if the contact at its level is detected. It worth to mention that, the results of analysis are not so sensitive to the changes of the stiffness of the impact elements simulating the collisions (Anagnostopoulos. S,1992, Anagnostopoulos. S,1988, Pantelides. C, \& Ma, X. 1998 \& Jeng. V, and Tzeng, W. 2000). Rayleight damping coefficients corresponding to a damping ratio of $5 \%$ for the first two modes (Clough and Penzien, 1993) were adopted. A damper with different damping coefficients was placed on the top floor of the 5-storey frame and connected to the same level of the other frame (10-storey or 15-storey), as shown in Fig. 3, that is represented by a dash pot. The investigated buildings were analyzed utilizing the time-history dynamic analysis under the excitation of three generated earthquakes having a response spectrum that matches 
that of the UBC-1994, with a peak ground acceleration of $0.2 \mathrm{~g}$. Figure 4 shows the three generated earthquakes GEN1, GEN2 and GEN3 with different duration, 20, 30, and 40 seconds respectively. A comparison between the computed response spectrum of the three generated earthquakes \& the target response spectrum of UBC-1994 are shown also in Figure 4 , which indicates that a very good agreement is achieved.

In order to investigate the effect of the separation distance to the pounding behavior of buildings and the effect of introducing dampers on the pounding behavior of the frames as well as determining the efficient value or the effective range of damping coefficient that can mitigate pounding significantly, three parametric studies were conducted as follows: -

1- No damper presented in the first parametric study while different separation distances were considered between the two frames in both pounding models.

2- In the second parametric study, a damper was placed between the two buildings for both pounding models.

3- Different damping coefficients of the dampers and different mass \& period ratios between the adjacent frames were investigated throughout the third parametric study using only the 10 storey-5 storey pounding model.

For each of the above cases, a time step equal $0.02 \mathrm{sec}$. was found to be reasonable for the analysis. COSMOS/M (1993) finite element package was used throughout the analysis.

\subsection{Discussion of Results}

\subsubsection{Pounding Effects on Buildings with Different Separation Distances}

The pounding behavior of buildings is greatly affected by the available separation distance provided between the two buildings, therefore it was decided to investigate the different pounding effects on buildings with different separation distance, and to determine the recommended separation distance to be provided between buildings in order to minimize or prevent pounding effects. Usually the separation distance between two adjacent buildings is expressed as a ratio from the Square Root of the Sum Squares (SRSS) of the maximum floor displacements of both buildings at the same level of the top floor of the lower building as if there is no pounding.

The different separation distances used in this study were chosen as follows:

a) Zero gap distance

b) $0.25 \mathrm{SRSS}$

c) $0.50 \mathrm{SRSS}$

d) $0.75 \mathrm{SRSS}$

e) SRSS

f) a wide gap distance that is sufficient for no pounding.

Where: $\quad$ SRSS $=\sqrt{S_{1}^{2}+S_{2}^{2}}$

S1: maximum deflection of the $5^{\text {th }}$ floor level of the tallest frame in case of no pounding S2: maximum deflection of the top floor level of the 5- storey frame in case of no pounding

Figures 5 represents the displacement-time history for the 10 -storey frame at the $5^{\text {th }}$ floor level and the 5-story frame at the top floor level under different gap distances subjected to Gen.1 earthquake for the 10 storey-5 storey pounding model. The vertical lines in the figures represent the time that the two frames pound to each other causing impact force on each frame. Generally it was observed, that the number of impacts between the adjacent frames 
decrease with the increase of the separation distances. It was also noted that, for both pounding models under the three generated earthquakes, no pounding occur between the two adjacent frames at separation distance equal to SRSS.

The maximum storey shear produced from pounding of both frames as result from each of the three generated earthquakes, were computed at different levels in both frames, where;

F1 : maximum storey shear force of the $6^{\text {th }}$ floor of the tallest frame.

F2 : maximum storey shear force of the $5^{\text {th }}$ floor of the tallest frame.

F3 : maximum base shear force of the tallest frame

F4 : maximum storey shear force of the top floor of the 5-storey frame.

F5 : maximum base shear force of the 10-storey frame.

The average maximum storey shear at different levels resulted from the three generated earthquakes were computed for each separation distance and compared to that of the case of no pounding, results are plotted for the 10 storey -5 storey pounding model and 15 storey -5 storey pounding model in Figure 7 and 8 respectively.

As can be noticed, that there are no significant change in the storey shear forces F1, F2, F3 of the tall frames by increasing the separation distance greater than 0.25 SRSS for both pounding models. However, increasing the separation distance has a significant effect on reducing the storey shear force of the top floor of the lower frame (F4), such result was also reported by Jeng. V, Tzeng. W, 2000 and Embaby. A, Mourad. S, 2000.

The base shear of the 5-storey frame (F5) was also not significantly affected by increasing the separation distance greater than 1/2 SRSS, however a remarkable reduction in the base shear (F5) can be resulted by providing a separation distance equal to 1/4 SRSS.

\subsubsection{Effect of placing a damper between the buildings on the pounding behavior}

Pounding effects can be greatly mitigated by reducing the dynamic response of both buildings. Increasing the inherent damping of the building can significantly reduce such dynamic response. However it is difficult from practical point of view to increase the inherent damping of the building to a level that reduces its dynamic response. It is decided to investigate the effect of placing an elasto- viscous damper at the top floor of the lower building to connect the two buildings at that level, and mitigating the pounding effects of both buildings. Both pounding models, 10 storey -5 storey and 15 storey -5 storey models, were investigated under the three generated earthquakes when both adjacent frames were separated by different separation distances. Three damping coefficient $(\mathrm{C})$ for the viscous damper were used in this study $(\mathrm{C}=100,200$ and $300 \mathrm{t} . \mathrm{sec} / \mathrm{m})$ in order to high light the effect of such damper on the pounding behavior, the results were compared with those obtained without placing any dampers.

For both pounding models, the average maximum shear force at different levels of the two buildings resulted from the three generated earthquakes and the corresponding maximum value were determined for different separation distance when using different damping coefficient and were compared to those obtained from cases of not using any dampers in Fig. 13 and 14 respectively. It can be noticed that the shear forces of the 10 -storey frame and the 15-storey frame F1, F2 and F3 are slightly reduced by placing dampers; however such reduction is not greatly affected by increasing the damping coefficients. With regard to the shear forces F 4 of the 5 storey frame it is noticed that it is significantly reduced for cases of 0 , 
0.25 SRSS, 0.50 SRSS, and 0.75 SRSS and this reduction increase with the increase of the damping coefficients in case of 0 , and 0.25 SRSS.

While the shear force F4, in case of separation distance equal to 0.50 SRSS, 0.75 SRSS and SRSS, was noticed to be slightly increased by increasing the damping coefficient from 100 to $300 \mathrm{t}$. sec./m. It is worth to mention that for the cases of separation distance equal to 0.75 SRSS and SRSS, there were no impact forces at all amount of damping coefficients, as discussed previously, however, the shear force F4 was increased slightly by adopting dampers with high values of damping coefficients. Such slight increase in shear force F4 is attributed to the fact that for the case of large separation distances and high damping coefficients, the damper acts as a rigid link connecting the light 5-storey frame to the heavy 10-storey frame which tends to increase the displacement of the 5-storey frame to produce high shear forces. The base shear of the 5-storey frame F5 was significantly reduced even when using small values of damping coefficients; however, increasing the damping coefficient has insignificant effect on reducing the base shear F5, as can be noticed from Figs 13 and 14.

\subsubsection{Efficient Value of Damping Coefficient}

It was found that the pounding behavior is greatly affected by the value of damping coefficient of the damper especially the impact forces and the shear forces at the top floor of the lower building. Therefore it was decided to determine the efficient value or the effective range of damping coefficient that can mitigate pounding significantly.

To investigate the effect of the periodic time ratios and the masses ratios between the adjacent buildings, into the damping coefficient of the damper, the first pounding model that consists of 10-storey frame \& 5-storey frame was used in this investigation but with different ratios of periodic times and different mass ratios. The studied cases are summarized in Table, it was decided to maintain the same ratios of period and masse in case 3 and case 4 , but with heavier masses in case 4, to investigate the effect of heavier masses on the effective range of damping coefficient to reduce both the impact forces and story shear F4. Only case 1 was subjected to the three generated earthquake Gen. 1, Gen. 2 and Gen. 3, while all the other cases were subjected to only one earthquake Gen. 1, since it was found from case 1 that there was a similar behavior under the three generated earthquakes specially for large values of damping coefficients.

For each of the five cases, different damping coefficients $(\mathrm{C})$ were used from $\mathrm{C}=0$ (case of no damper) up to $1000 \mathrm{t} . \mathrm{sec} / \mathrm{m}^{2}$, and with a gap distance equal to zero which is considered as the most sever case of pounding as was previously demonstrated.. The variation of the maximum shear forces at the top storey of the 5-storey frame (F5) for all five cases, resulted by increasing the damping coefficient of the damper is shown in Fig 16. It can be observed that the minimum shear forces F5 occurred at damping coefficient ranging from 100 to $500 \mathrm{t} . \mathrm{sec}^{2}$. $/ \mathrm{m}$, even for case 3 and case 4, except that higher shear force F5 was observed in case 4 because of the existing of higher mass as compared to case 3 .

\section{VERIFICATION OF RESULTS AS COMPARED TO DIFFERENT INTERNATIONAL CODES}

It was concluded from the previous parametric study that providing a separation distance equal to SRSS of the maximum floor displacements of both frames at the top floor of the lower frame, will result in producing no pounding effects on both frames. It was of interest to compare the resulted separation distances (SRSS) obtained from the studied pounding models with those computed from the different international codes, in order to investigate its 
application on the studied cases to examine its conservation. The required separation distances specified by some international codes are presented as follows: -

a) National Building Code of Canada (NBCC 1990) specifies that, Buildings shall be separated by the sum of their anticipated maximum deflections.

b) International Building Code (IBC-2003 Specifies that, adjacent buildings on the same property shall be separated by at least $S_{m T}$ where:

$$
S_{m T}=\sqrt{S_{m 1}^{2}+S_{m 2}^{2}} ; S_{m 1} \text { and } S_{m 2} \text { are the lateral displacements of the adjacent buildings. }
$$

c) Euro Code No.9.2003 specifies that, the minimum separation between two buildings shall not be less than the square root of the sum square for the lateral displacements of the adjacent buildings in case of no pounding. If the adjacent buildings have the same storey heights the separation distance may be reduced by a factor equal to 0.7

d) Egyptian Code for Calculating Loads and Forces in Structural and Masonry Works, 2004 specifies that, the separation distance must be equal to the absolute sum of the maximum displacement of both buildings (ABS) for adjacent buildings having unequal storey height. If the adjacent buildings have the same storey heights the separation distance may be reduced by a factor equal to 0.7 where;

$A B S=S_{1}+S_{2} ; S_{1}$ and $S_{2}$ are the maximum horizontal displacements of the adjacent resulted from either elastic time history analysis or from the designed base shear after multiplying it by the force modification factor (R).

The resulting obtained separation distances for the two pounding models that was found to be equal to the SRSS value of the maximum floor displacements of both frames at the level of the lower frame (S1 and S2), as well as the required separation distances specified by the provisions of some different international codes for preventing the occurrence of pounding are given in Table 4. The values of separation distances specified by the NBCC-1990 are over estimated as compared to the SRSS values by about $40 \%$.

As can be noted that the separation distances specified by IBC-2003 are equal to the resulting values for different earthquakes, since the IBC-2003 Code specifies a minimum separation distance equal to SRSS. Such comparison implies that the IBC-2003 specifies values of separation distances, which was verified from the parametric study that will be sufficient to avoid any pounding effects. The values of Eurocode-2003, are under estimating the resulting separation distances, however, the specified distance of the Egyptian code 2004 are slightly less than the resulting separation distances.

\section{CONCLUSIONS}

In the case of adjacent buildings with unequal heights, pounding can create serious problems, especially at the top floor of the lower building. Pounding effects are more pronounced in such cases because of large difference in total mass and periods of both buildings that can penalize greatly the smaller building. However, providing an at-rest building separation distance equal to the Square Root of Sum Square (SRSS) of peak building displacements resulted from the non-pounding condition was found to be an effective way to avoid pounding effects for new constructed buildings. Both the impact forces and the top story shear of the lower frame are significantly reduced by increasing the separation distance, however the high impact forces that results from small separation distance are mainly converted to high inertia forces at the top floor of the lower frame to produce high floor accelerations that affect the frame dynamic response. It is also noted that introducing dampers between two adjacent buildings significantly reduce both the impact force and the storey shear force at the top of the lower building, especially for cases where the existing separation distances are not sufficient 
to avoid pounding. Therefore, introducing dampers with appropriate damping coefficients between two existing buildings can be an effective way to mitigate pounding effects. For the buildings models presented in this study, it was found that, the efficient damping coefficient of the damper ranged from 100 to $500 \mathrm{t} . \mathrm{sec}^{2} / \mathrm{m}$. It was found that such range of damping coefficients was applicable to buildings with mass ratios ranging from 1.10 to 2.03 and period ratios ranging from 1.30 to 1.79 , even if both buildings have higher values of masses and maintaining the same mass ratios. According to the results of the parametric studies that were carried out in this research, it was found that IBC-2003 specifies the same values as were obtained from this study, while the Eurocode-2003 underestimates the separation distances by a bout 30\% and the NBCC-1990_was overestimating the separation distance by values that can reach up to $40 \%$. It was noticed that the separation distance obtained by the provisions of Egyptian code-2004 are slightly less than those required for no-pounding effects. Therefore, applying such values may cause slight pounding effects on the buildings with minor damage.

\section{REFERENCES}

Anagnostopoulos, S., and Piliopoulos, K., 1990, "Analysis of Building Pounding Due to Earthquake", Structural Dynamics, pp.479-484.

Angagnostopoulos, S.,1992, "An Investigation of Earthquake Induced Pounding Between Adjacent Buildings", Earthquake Engineering and Structural Dynamics,Vol.21, pp.289-302.

Angagnostopoulos,S.,1988, "Pounding of Building in Series During Earthquake", Earthquake Engineering And Structural Dynamics, Vol. 16, pp.443-456.

Clough, R. and PENSIEN, J., 1993, "Dynamics of Structures”, McGraw Hill Book Company.

Cosmos/M User Guide, 1993, Structural Research and Analysis Cooperation, $28^{\text {th }}$ Street, Suit 1000, Santa Monica, California, 90405.

Egyptian Code of Practice for Design and Construction of Reinforced Concrete Structures, Ministeral Decree, No. 203-2001.

EL-Naggar S. and Soliman M, 2003, "Pounding Effects On Building Seismic Response", Proc. of the $9^{\text {th }}$ Arab Structural Engineering Conf., Nov. 29- Dec. 1, 2003, Abu Dhabi, UAE.

Emilio, R. and Robert. M., 1986, "The 1985 earthquake: Causes and Effects in MexicoCity", Report by Subcommittee on Norms and Construction Procedures of the Committee for Mexico City's Metropolitan Area, National Reconstruction Commission, Concrete International.

Embaby, A. and Mourad, S., 2000 " Effect of Dampers on the Pounding Response of Adjacent Buildings" Civil Engineering Research Magazine, Al Azhar University, Vol. (22) No. (4).

Filiatrault A., Cervantes M., Folz B. And Prion H., 1994, "Pounding of buildings during earthquake: a Canadian perspective", Can .J. Civ. 21.251-265.

Filiatrault, A. and Cervantes, M., 1995, "Separation Between Building to Avoid Pounding During Earthquake", Canadian Journal Of Civil Engineering, Vol. 22, pp.164-179. 
International Building Code, IBC-2003, International Code Council, USA

Jeng Hsiang Lin, Cheng Chiang Weng, 2001 "Spectral analysis on Pounding Probability of adjacent buildings", Engineering Structures Vol. 23, pp 768-778.

Jeng V., and Tzeng W., 2000 "Assessment of Seismic Pounding hazard for Taipei City", Engineering Structures, Vol 22, pp. 459-471.

Kawshima, K. 1992 " Effectiveness of the variable damper for reducing seismic response of highway bridges against earthquakes " Proc. $2^{\text {nd }}$ US-Japan Workshop on Earthquake Protective System for Bridges, J-2, PWRI, Tsukuba, Japan.

Kobori T., Yamada T., Takenaka Y., Maeda Y., \& Nishimura I. 1988 " Effect of dynamic tuned connector on reduction of seismic response: application to adjacent office buildings." Proceedings of the Ninth world Conference on Earthquake Engineering, vol. V, Tokyo-Kyoto, Japan.

Maiso B., and Kasai K., 1990," Analysis for Type of Structural Pounding", Journal of Structural Engineering, ASCE, Vol. 116, No.4.

Maiso B., and Kasai K., 1992,"Dynamic of Pounding when Two Buildings Collide", Earthquake Engineering and Structural Dynamics, Vol. 21, PP.771-786.

Pantelides, C, and Ma, X., 1998, "Linear And Nonlinear Pounding of Structural Systems", Computer \& Structures, Vol. 66, No.1, pp. 79-92.

Samali . B and Kwok. K, 1995 " Use of viscoelastic dampers in reducing wind-and earthquake- induced motion of building structures " Engineering structures Journal, Vol. 17. No. 9. pp. 639-654

Westermo, B.,1989, "The Dynamic of Inter-structural Connection to Prevent Pounding", Earthquake Engineering And Structural Dynamics, Vol. 16,PP.687-699.

Xu Y., Zhan S., and Ko J., 1999, "Experimental Investigation of Adjacent Building Connected By Fluid Damper", Earthquake Engineering And Structural Dynamics, Vol. 28, PP.609-631.

Xu Y., , He Q. and Ko J., 1999 , "Dynamic response of damper-connected adjacent buildings under earthquake excitation” Engineering Structures Vol 21, pp. 135-148. 
Proceedings of the 6th ICCAE Conf. 16 -18 May, 2006

Table (1) : Dimensions of members for the studied frames

\begin{tabular}{|c|c|c|c|c|}
\hline & Floors & $\begin{array}{c}\text { Exterior } \\
\text { column } \\
(\mathrm{cm})\end{array}$ & $\begin{array}{l}\text { Interior } \\
\text { column } \\
(\mathrm{cm})\end{array}$ & $\begin{array}{c}\text { Beam } \\
(\mathrm{cm})\end{array}$ \\
\hline \multirow{2}{*}{$\begin{array}{l}\text { 5- Story } \\
\text { frame }\end{array}$} & Ground to second & $30 \times 60$ & $30 \times 80$ & $30 \times 70$ \\
\hline & Third to fourth & $30 \times 50$ & $30 \times 70$ & $30 \times 70$ \\
\hline \multirow{5}{*}{$\begin{array}{l}\text { 10-storey } \\
\text { frame }\end{array}$} & Ground to first & $30 \times 80$ & $35 \times 110$ & $30 \times 70$ \\
\hline & $2^{\text {nd }}$ to $3^{\text {rd }}$ & $30 \times 70$ & $30 \times 100$ & $30 \times 70$ \\
\hline & $4^{\text {th }}$ to $6^{\text {th }}$ & $30 \times 60$ & $30 \times 90$ & $30 \times 70$ \\
\hline & $7^{\text {th }}$ to $8^{\text {th }}$ & $30 \times 50$ & $30 \times 80$ & $30 \times 70$ \\
\hline & $9^{\text {th }}$ & $30 \times 50$ & $30 \times 70$ & $30 \times 60$ \\
\hline \multirow{8}{*}{$\begin{array}{l}\text { 15-story } \\
\text { frame }\end{array}$} & Ground to first & $40 \times 120$ & $40 \times 150$ & $30 \times 70$ \\
\hline & $2^{\text {nd }}$ to $3^{\text {rd }}$ & $35 \times 110$ & $40 \times 140$ & $30 \times 70$ \\
\hline & $4^{\text {th }}$ to $5^{\text {th }}$ & $30 \times 100$ & $40 \times 130$ & $30 \times 70$ \\
\hline & $6^{\text {th }}$ to $7^{\text {th }}$ & $30 \times 90$ & $40 \times 120$ & $30 \times 70$ \\
\hline & $8^{\text {th }}$ to $9^{\text {th }}$ & $30 \times 80$ & $35 \times 110$ & $30 \times 70$ \\
\hline & $10^{\text {th }}$ to $11^{\text {th }}$ & $30 \times 70$ & $30 \times 100$ & $30 \times 70$ \\
\hline & $12^{\text {th }}$ to $13^{\text {th }}$ & $30 \times 60$ & $30 \times 90$ & $30 \times 70$ \\
\hline & $14^{\text {th }}$ & $30 \times 50$ & $30 \times 80$ & $30 \times 60$ \\
\hline
\end{tabular}

Table (2) : The period of vibration of the first five modes for studied frames

\begin{tabular}{|c|c|c|c|c|c|c|c|}
\hline & \multirow[b]{2}{*}{ Frame I.D } & \multirow{2}{*}{$\begin{array}{c}\text { total } \\
\text { masses } \\
\text { (ton) }\end{array}$} & \multicolumn{5}{|c|}{ Period of vibration (sec.) } \\
\hline & & & $\begin{array}{c}1^{\text {st }} \\
\text { mode }\end{array}$ & $\begin{array}{c}2^{\text {nd }} \\
\text { mode }\end{array}$ & $\begin{array}{c}3^{\text {rd }} \\
\text { mode }\end{array}$ & $\begin{array}{c}4^{\text {th }} \\
\text { mode }\end{array}$ & $\begin{array}{c}5^{\text {th }} \\
\text { mode }\end{array}$ \\
\hline \multirow{5}{*}{$\begin{array}{l}\text { 5- storey } \\
\text { frame }\end{array}$} & $F R_{5-1}$ & 456.6 & 0.787 & 0.259 & 0.142 & 0.099 & 0.073 \\
\hline & $F R_{5-2}$ & 640.0 & 0.94 & 0.310 & 0.168 & 0.116 & 0.085 \\
\hline & $F R_{5-3}$ & 840.0 & 1.08 & 0.355 & 0.193 & 0.133 & 0.098 \\
\hline & $F R_{5-4}$ & 1100.0 & 1.238 & 0.406 & 0.220 & 0.152 & 0.112 \\
\hline & $F R_{5-5}$ & 1860.0 & 1.608 & 0.528 & 0.287 & 0.198 & 0.145 \\
\hline \multirow{3}{*}{$\begin{array}{l}\text { 10-storey } \\
\text { frame }\end{array}$} & $F R_{10-1}$ & 925.5 & 1.41 & 0.452 & 0.257 & 0.18 & 0.135 \\
\hline & $F R_{10-2}$ & 1400.0 & 1.842 & 0.594 & 0.335 & 0.236 & 0.176 \\
\hline & $F R_{10-3}$ & 2360.0 & 2.392 & 0.771 & 0.435 & 0.306 & 0.228 \\
\hline $\begin{array}{c}\text { 15- storey } \\
\text { frame }\end{array}$ & $F R_{15-1}$ & 1394.0 & 1.92 & 0.632 & 0.351 & 0.236 & 0.179 \\
\hline
\end{tabular}


Table (3): Ratios of periods and masses for the studied cases

\begin{tabular}{|c|c|c|c|c|c|c|}
\hline & \multicolumn{2}{|c|}{ 10-storey frame } & \multicolumn{2}{|c|}{ 5-storey frame } & \multirow[b]{2}{*}{$\mathrm{T}_{1} / \mathrm{T}_{2}$} & \multirow[b]{2}{*}{$\mathrm{M}_{1} / \mathrm{M}_{2}$} \\
\hline & $\begin{array}{c}\text { Periodic } \\
\text { time }\left(\mathrm{T}_{1}\right) \\
(\mathrm{sec})\end{array}$ & $\begin{array}{c}\text { Total mass } \\
\left(\mathrm{M}_{1}\right) \\
(\text { ton }) \\
\end{array}$ & $\begin{array}{c}\text { Periodic } \\
\text { time }\left(\mathrm{T}_{2}\right) \\
(\mathrm{sec})\end{array}$ & $\begin{array}{c}\text { Total mass } \\
\left(\mathrm{M}_{2}\right) \\
(\mathrm{ton})\end{array}$ & & \\
\hline Case 1 & 1.41 & 925.5 & 0.79 & 456.6 & 1.79 & 2.03 \\
\hline Case 2 & 1.41 & 925.5 & 0.94 & 640.0 & 1.49 & 1.45 \\
\hline Case 3 & 1.84 & 1400.0 & 1.24 & 1100.0 & 1.49 & 1.27 \\
\hline Case 4 & 2.39 & 2360.0 & 1.61 & 1860.0 & 1.49 & 1.27 \\
\hline Case 5 & 1.41 & 925.5 & 1.08 & 840.0 & 1.30 & 1.10 \\
\hline
\end{tabular}

Table (4): Comparison between the resulting separation distances (SRSS) with international codes

\begin{tabular}{|c|c|c|c|c|c|c|c|c|}
\hline & 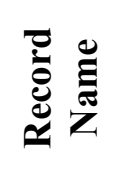 & $\underbrace{\overparen{E}}_{*}$ & 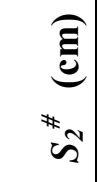 & 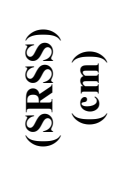 & 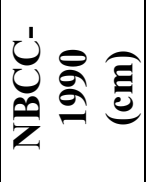 & 灾 & 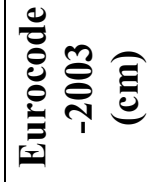 & 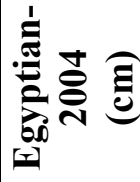 \\
\hline \multirow{3}{*}{ 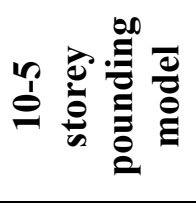 } & Gen.1 & 9.5 & 8.2 & 12.5 & 17.9 & 12.5 & 8.75 & 12.5 \\
\hline & Gen.2 & 7.2 & 7.1 & 10.1 & 14.3 & 10.1 & 7.07 & 10.0 \\
\hline & Gen.3 & 9.4 & $\vee, \wedge$ & 12.2 & 17.2 & 12.2 & 8.54 & 12.0 \\
\hline \multirow{3}{*}{ 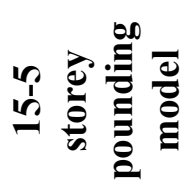 } & Gen.1 & 6.1 & $v, v$ & 9.8 & 13.8 & 9.8 & 6.86 & 9.7 \\
\hline & Gen.2 & 5.9 & $v, 1$ & 9.2 & 12.95 & 9.2 & 6.44 & 9.1 \\
\hline & Gen.3 & 6.2 & $\vee, \wedge$ & 10.0 & 14 & 10.0 & 7.00 & 9.8 \\
\hline
\end{tabular}

$* S_{1}$ is the maximum displacement of the $5^{\text {th }}$ floor for the 10 -storey frame

$\# S_{2}$ is the maximum displacement of the $5^{\text {th }}$ floor for the 5 -storey or the 15 -storey frame 

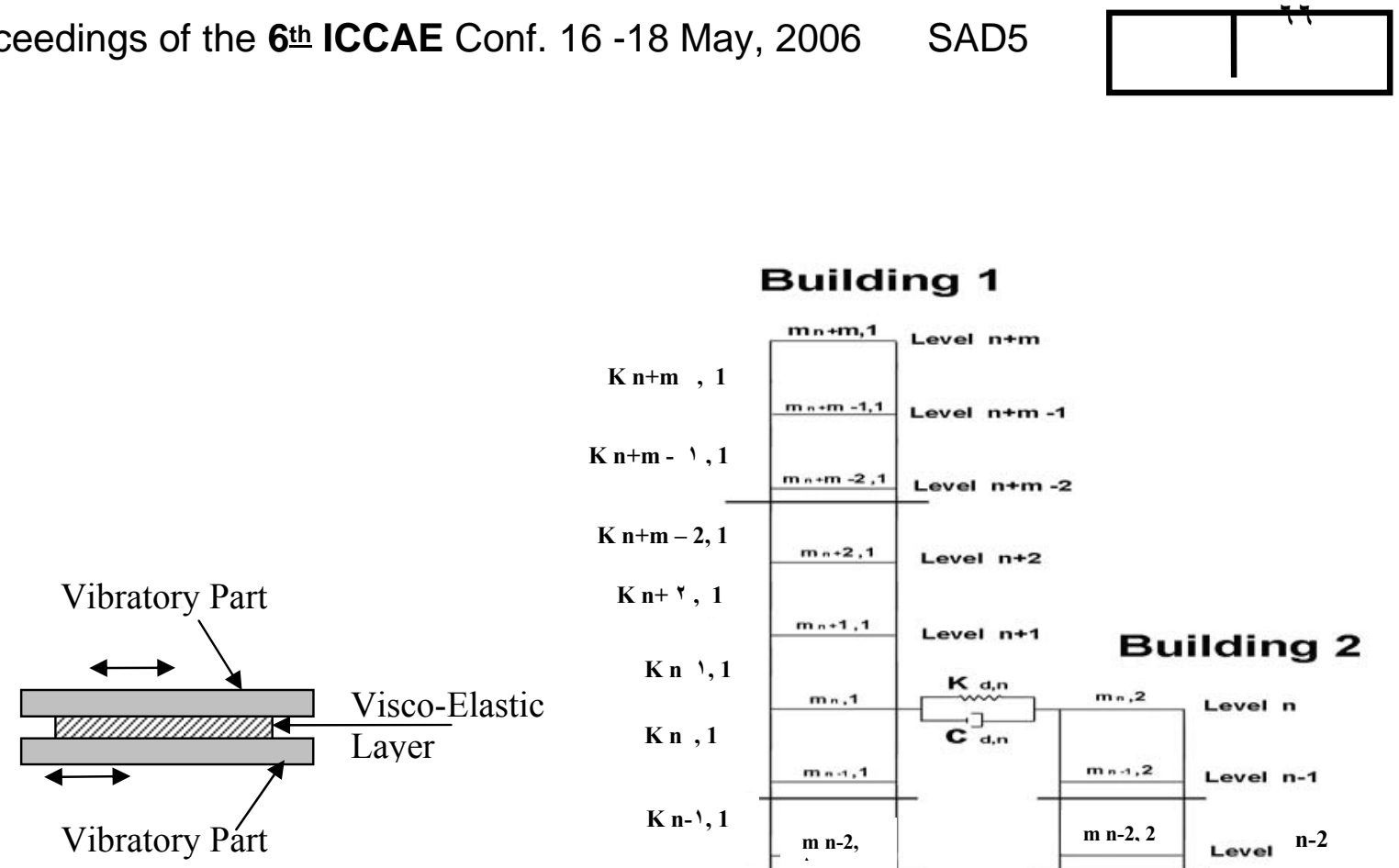

Fig. 1: Visco-Elastic Damper

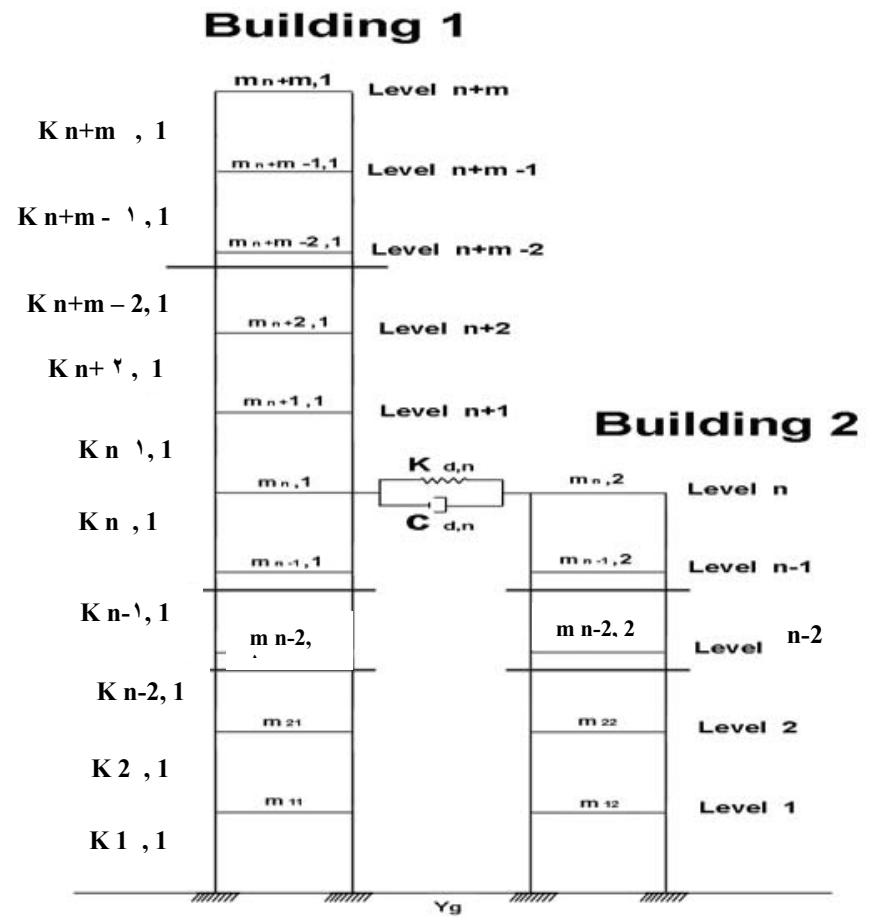

Fig. 2: Model Idealization

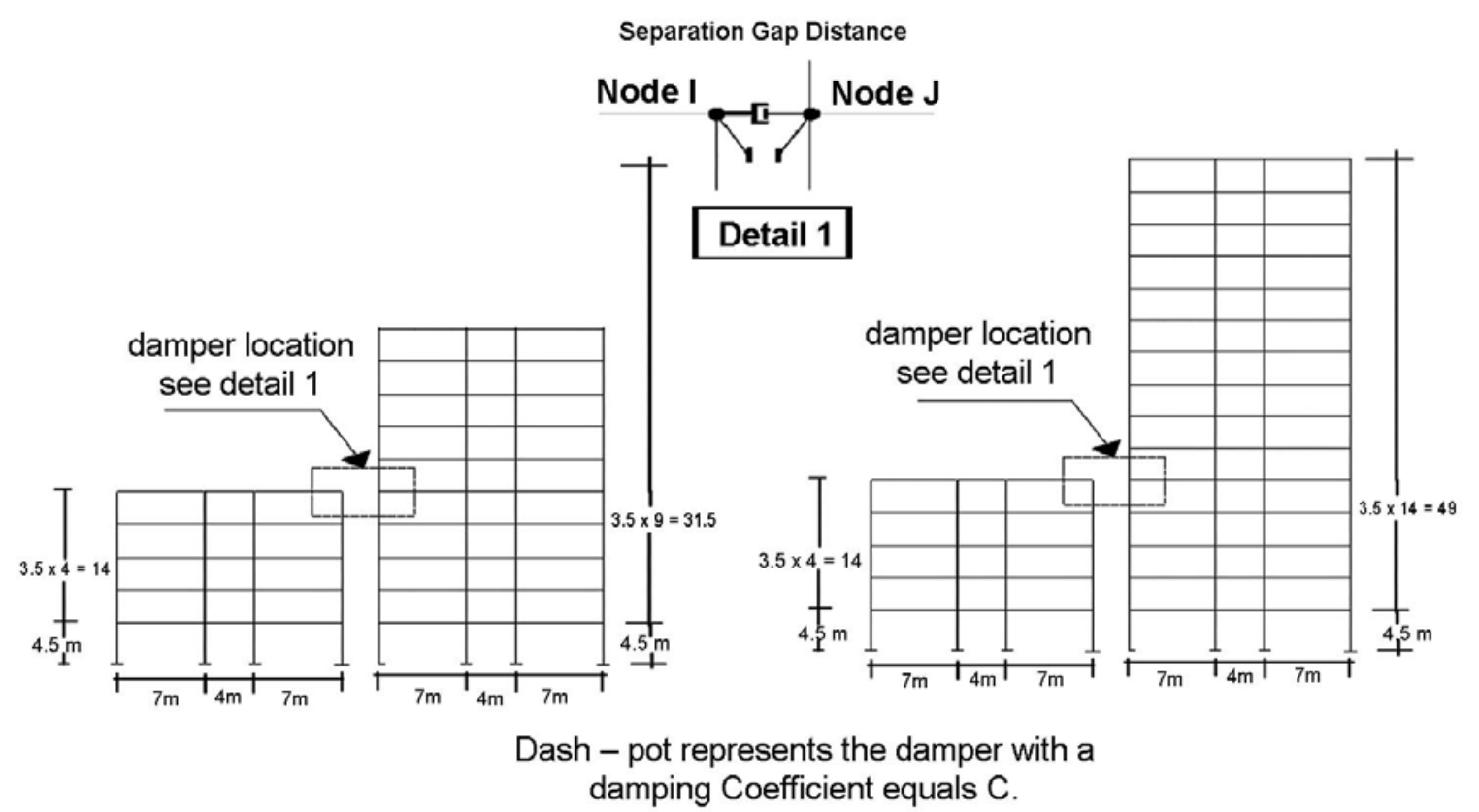

a) 10 -5 storey pounding model

b) 15-5 storey pounding model 


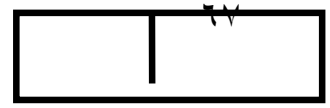

Fig. 3 : Studied Pounding Models
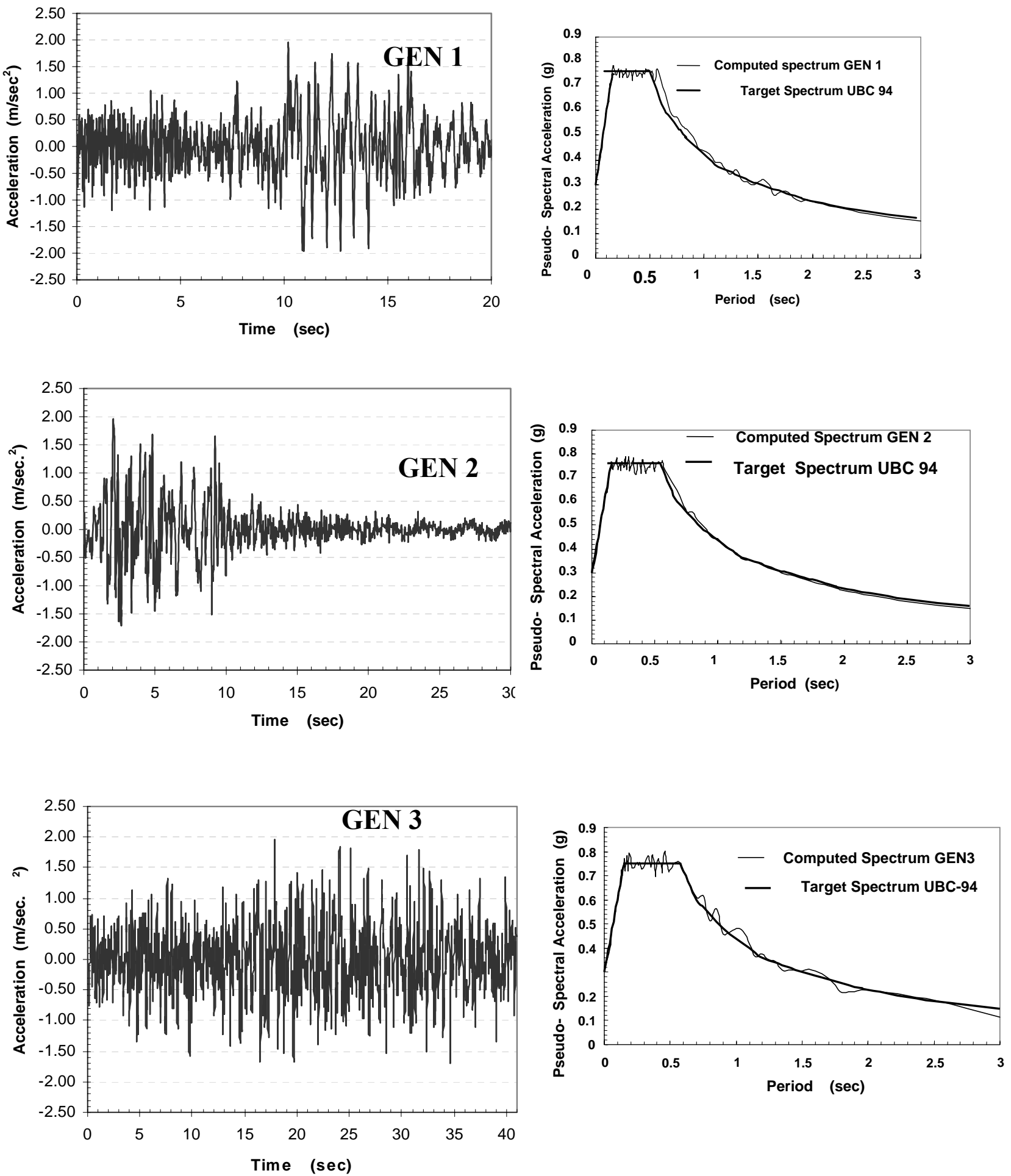

Fig. 4: The three generated earthquakes and the corresponding computed spectrum 
Proceedings of the 6th ICCAE Conf. 16 -18 May, 2006
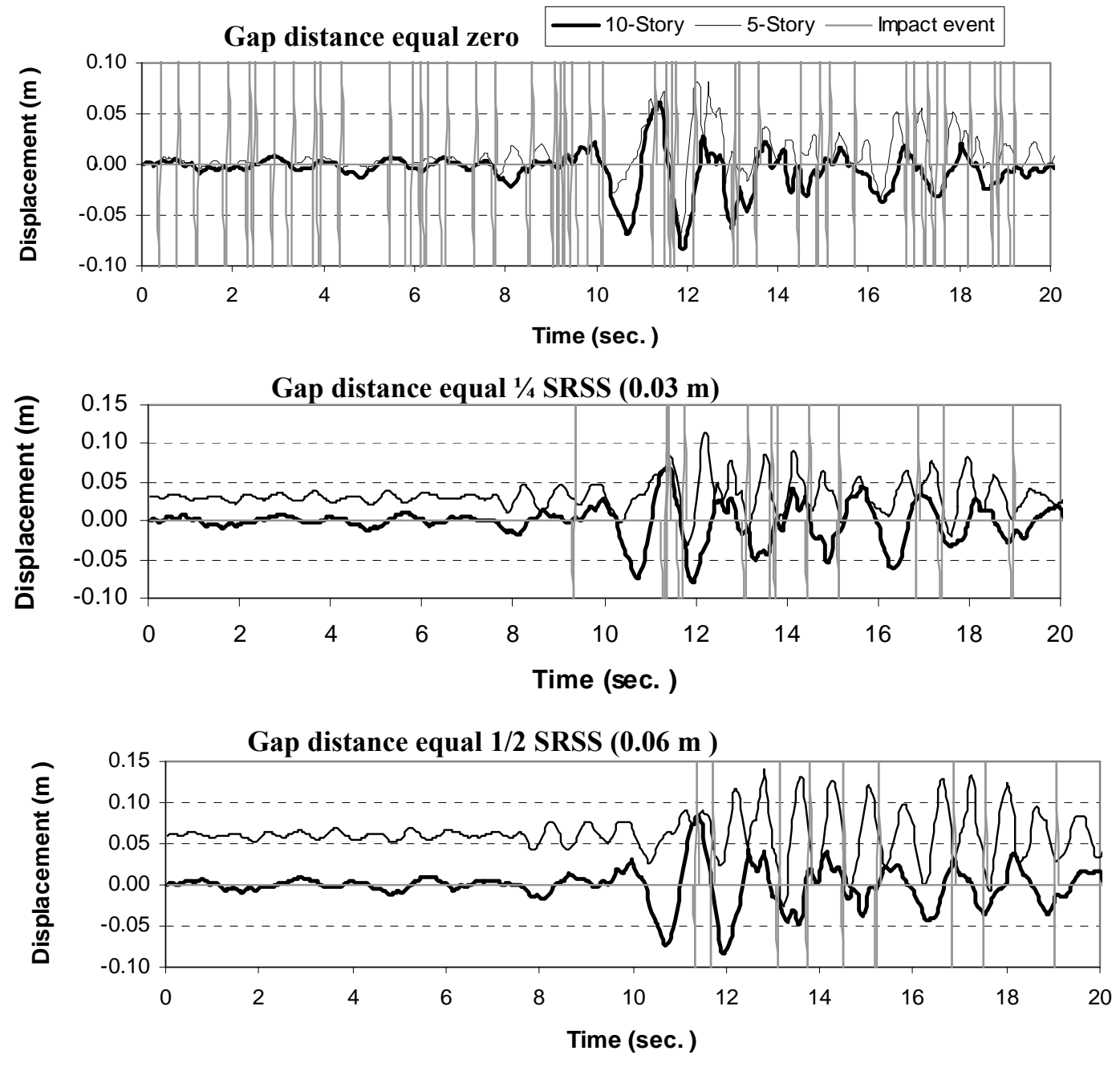

Gap distance equal 3/4 SRSS (0.09 m) )

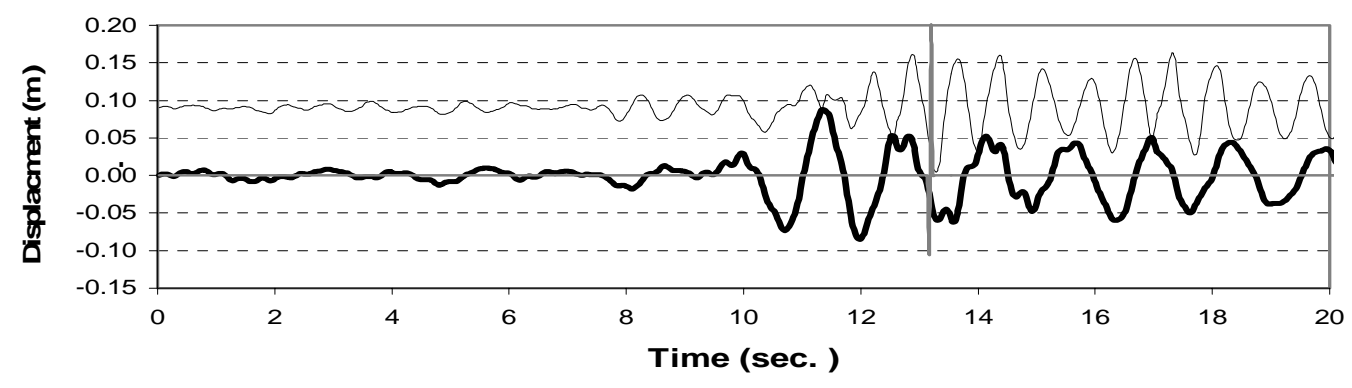


Proceedings of the 6th ICCAE Conf. 16 -18 May, 2006

SAD5
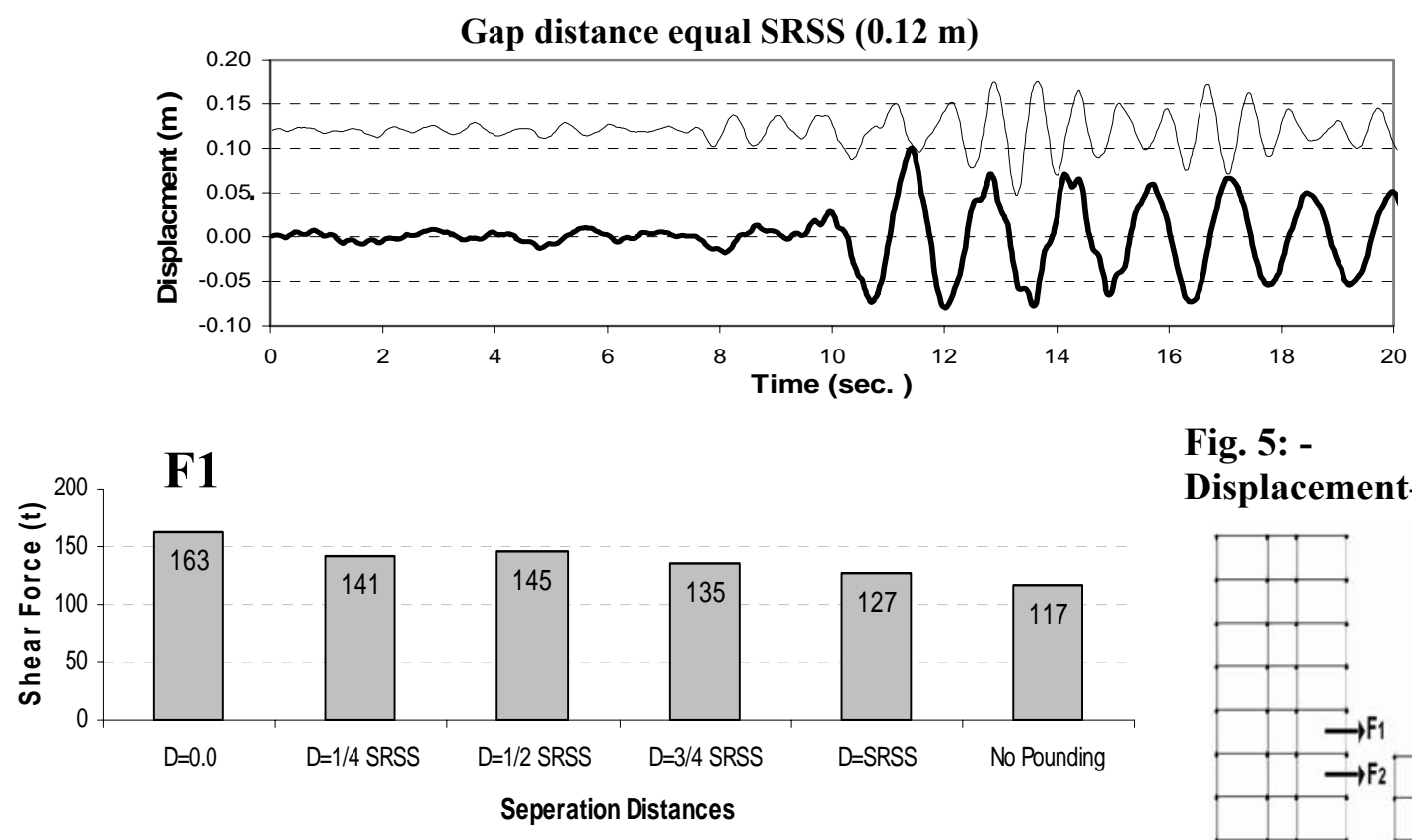

Fig. 5: -

Displacement- time
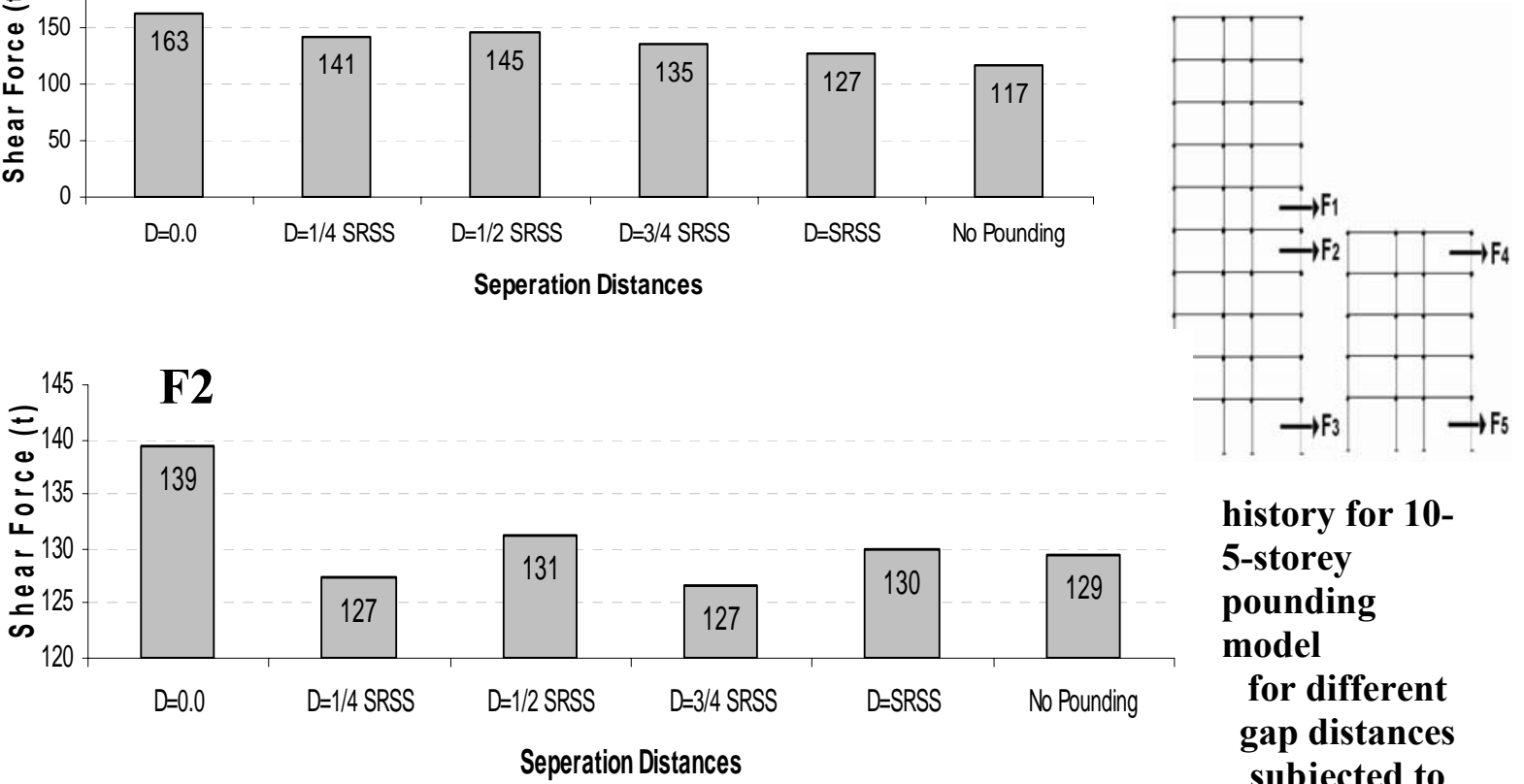

history for 10-

5-storey pounding model for different gap distances subjected to

F3 record Gen.1
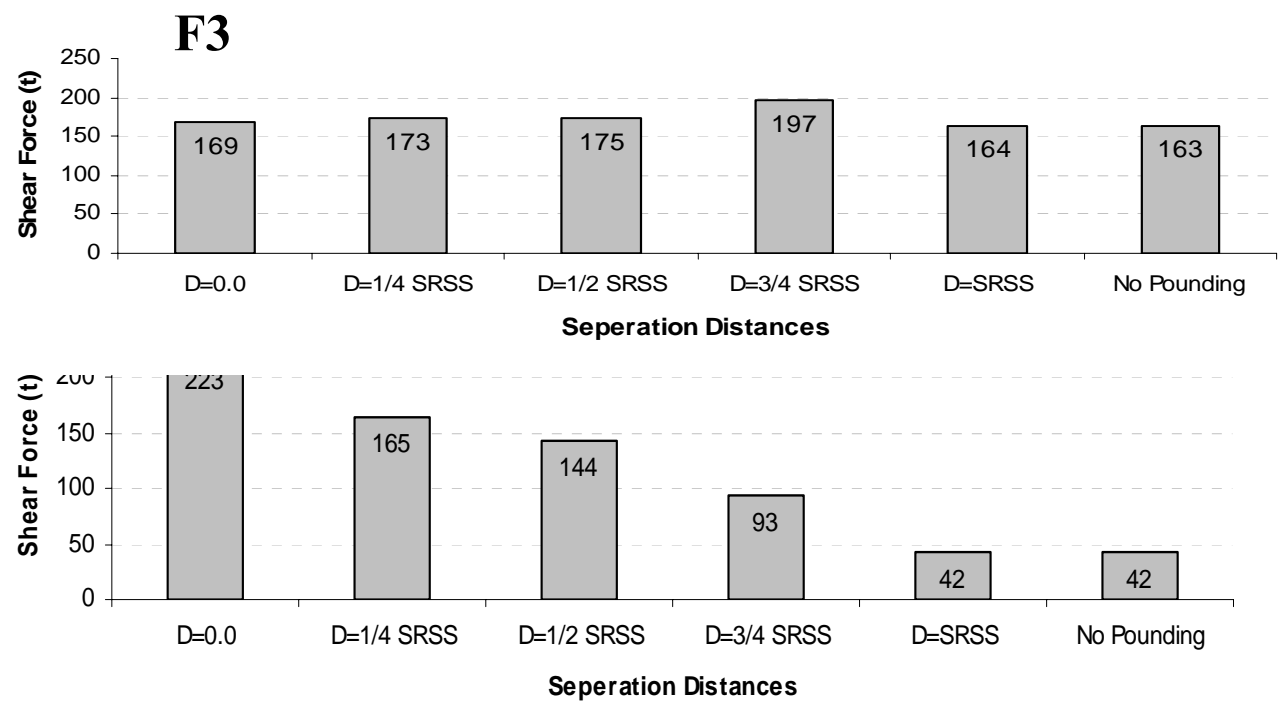


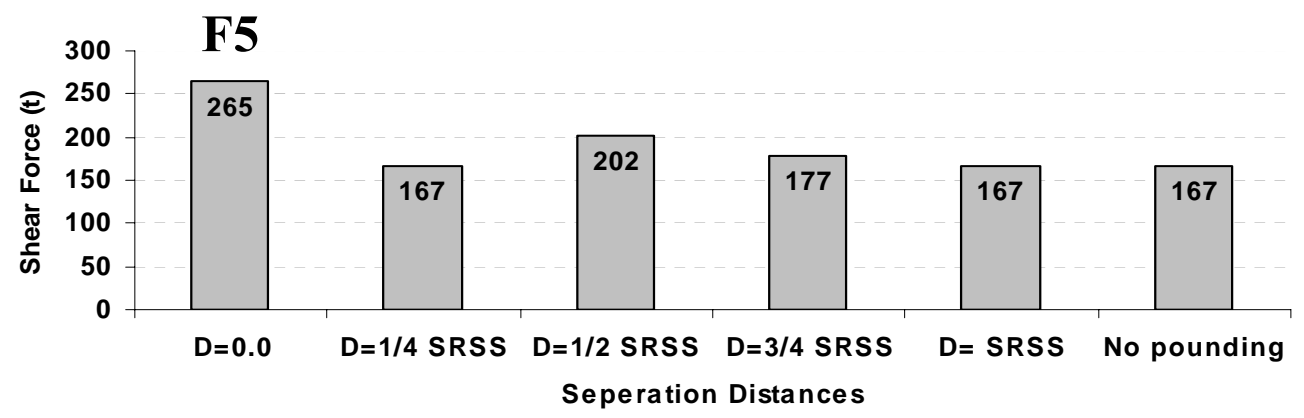

Fig. 6 : Average maximum shear forces in different levels for the 10-5 storey pounding model as resulted from the three generated earthquakes.

F1
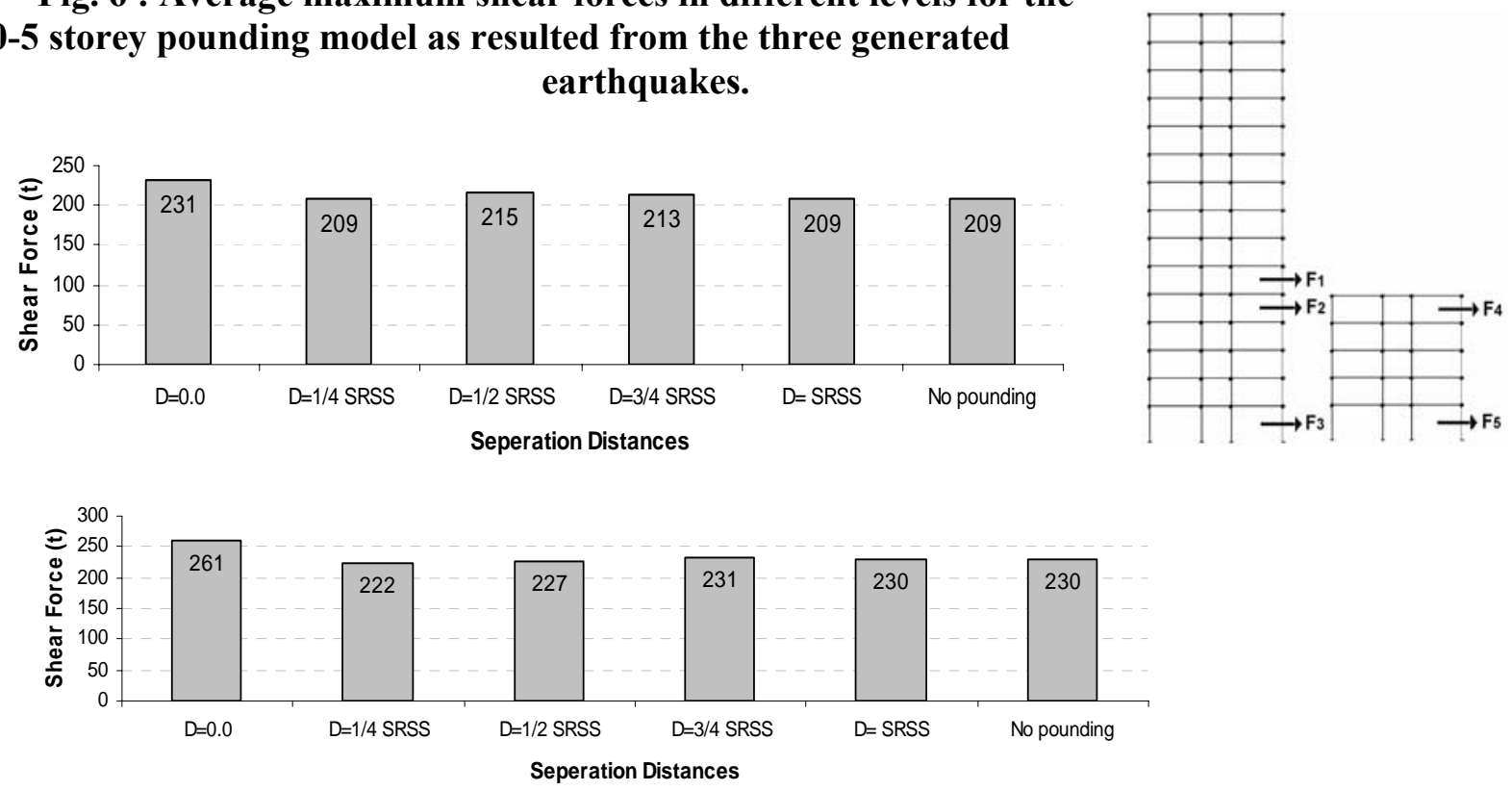

F2 
F3

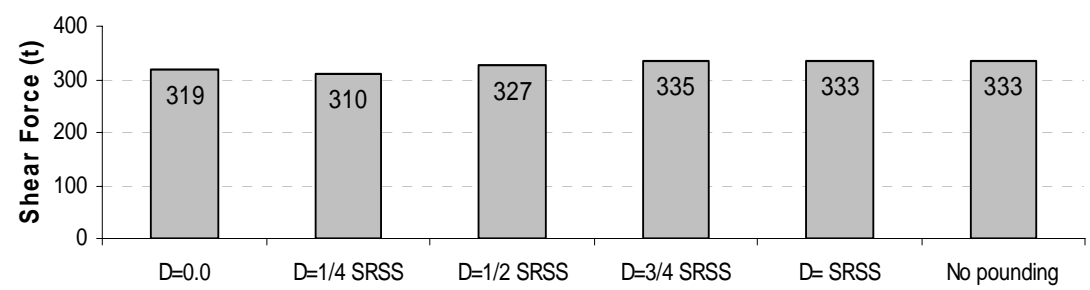

F4

Seperation Distances

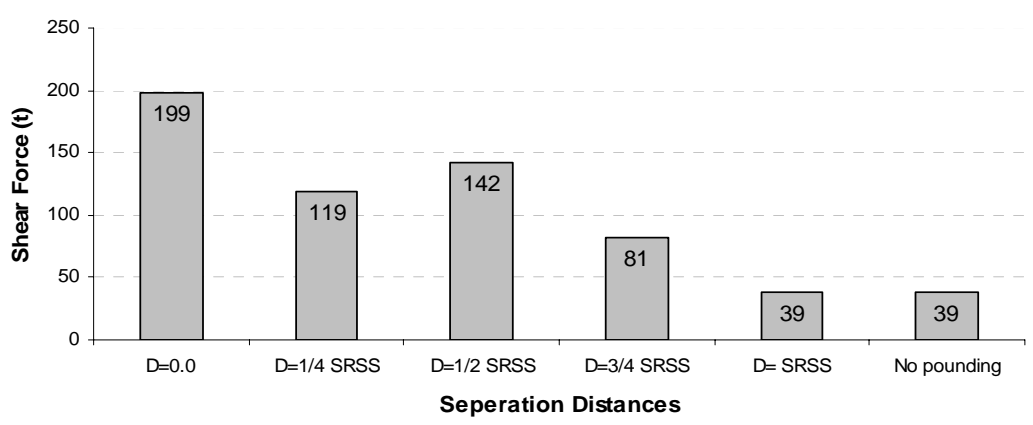

F5

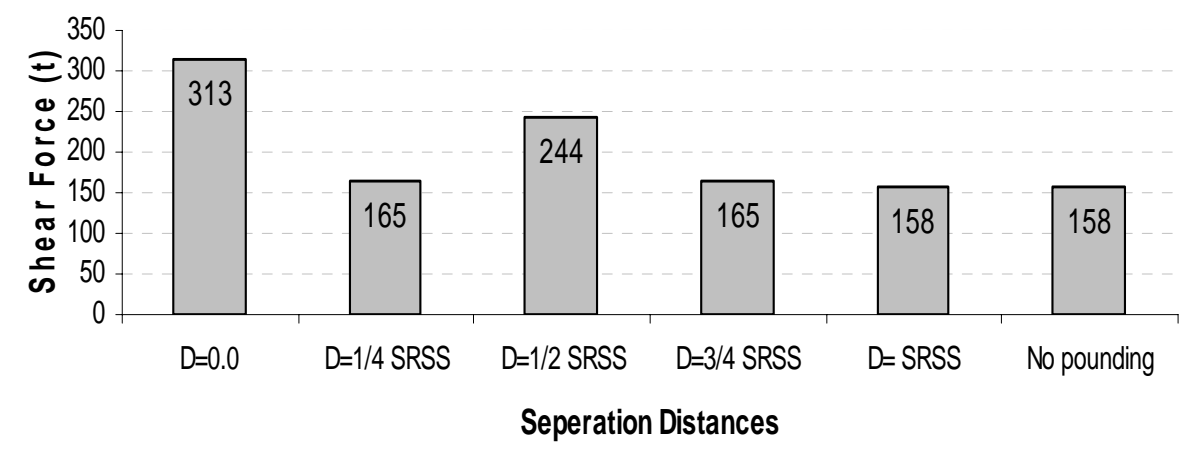

Fig. 7: Average maximum shear forces in different levels for the 15-5 storey pounding model as resulted from the three generated earthquakes.

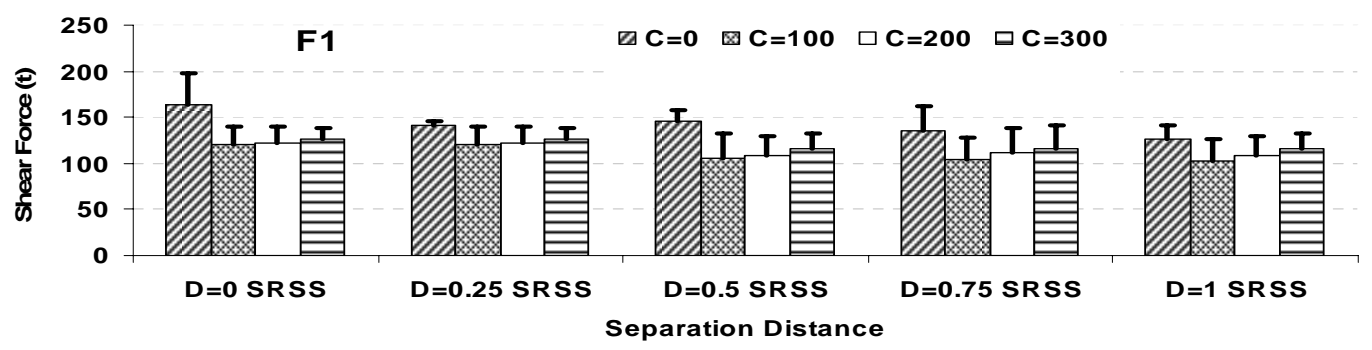


Proceedings of the 6 th ICCAE Conf. 16 -18 May, 2006
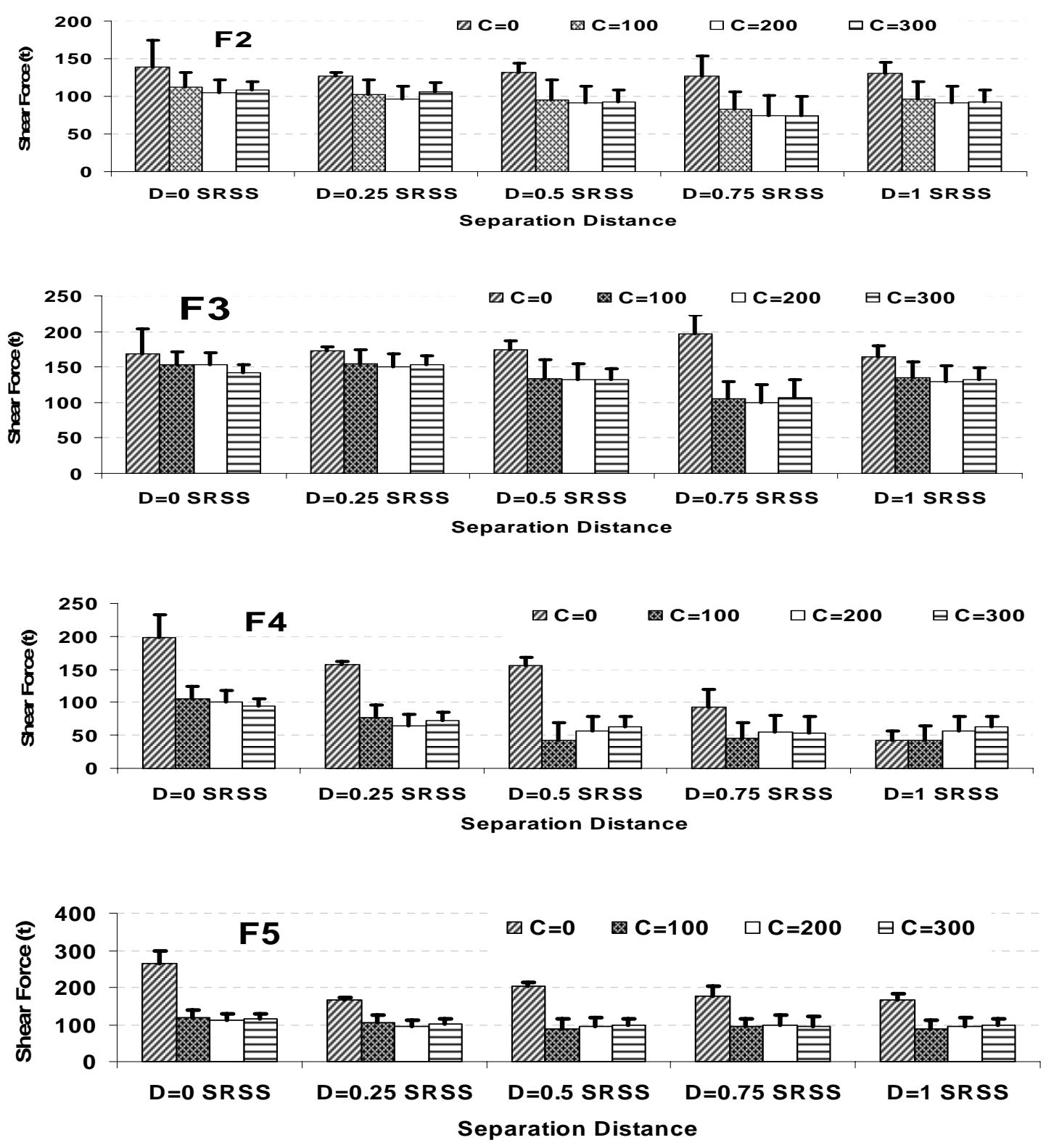

Fig. 8 : Average maximum and maximum maximum shear forces at different levels of frames for different separation distances and different damping coefficients for the 10-5 storey model 

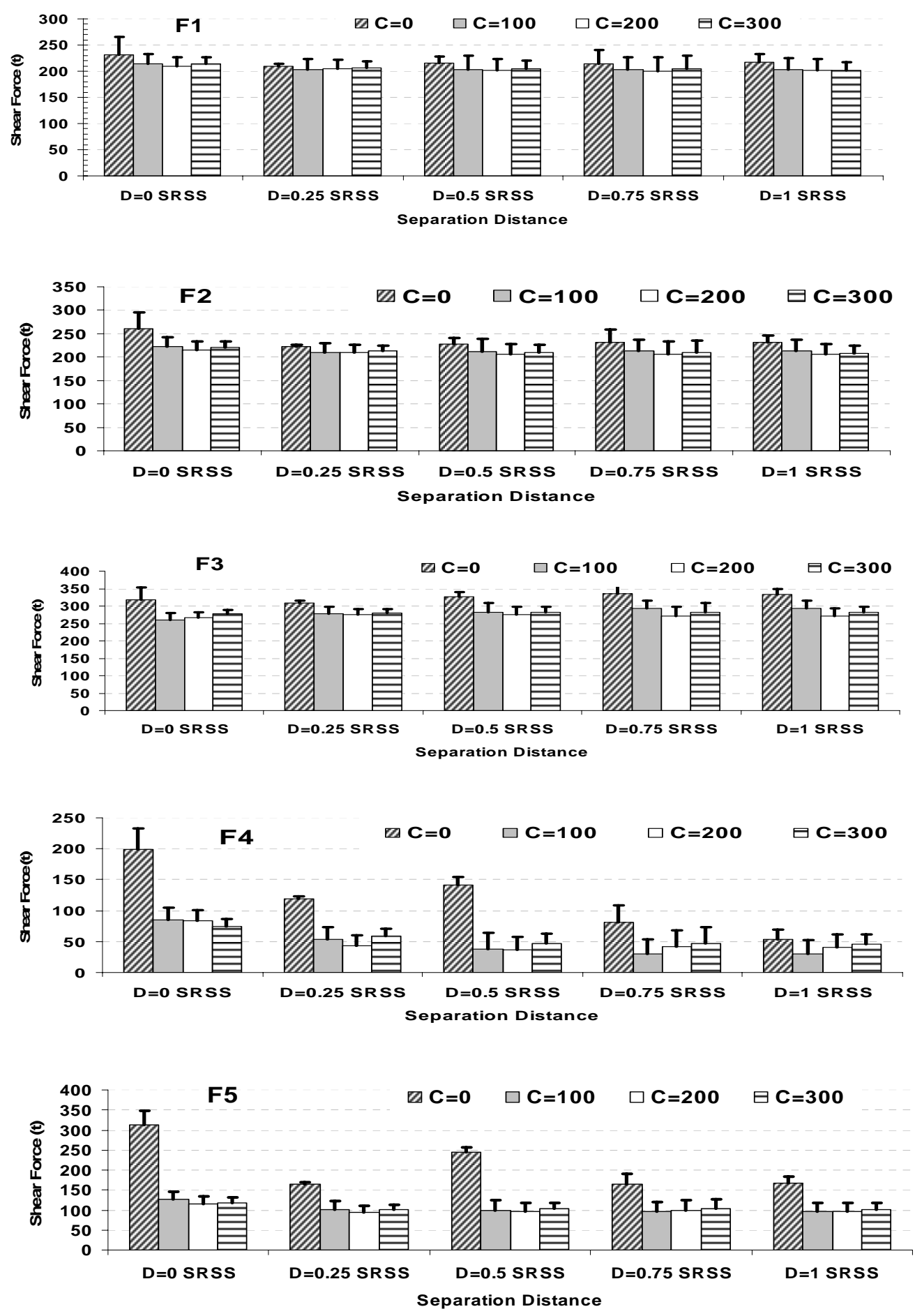

Fig. 9 : Average maximum and maximum maximum shear forces at different levels of frames for different separation distances and different damping coefficients for the 15-5 storey mode 

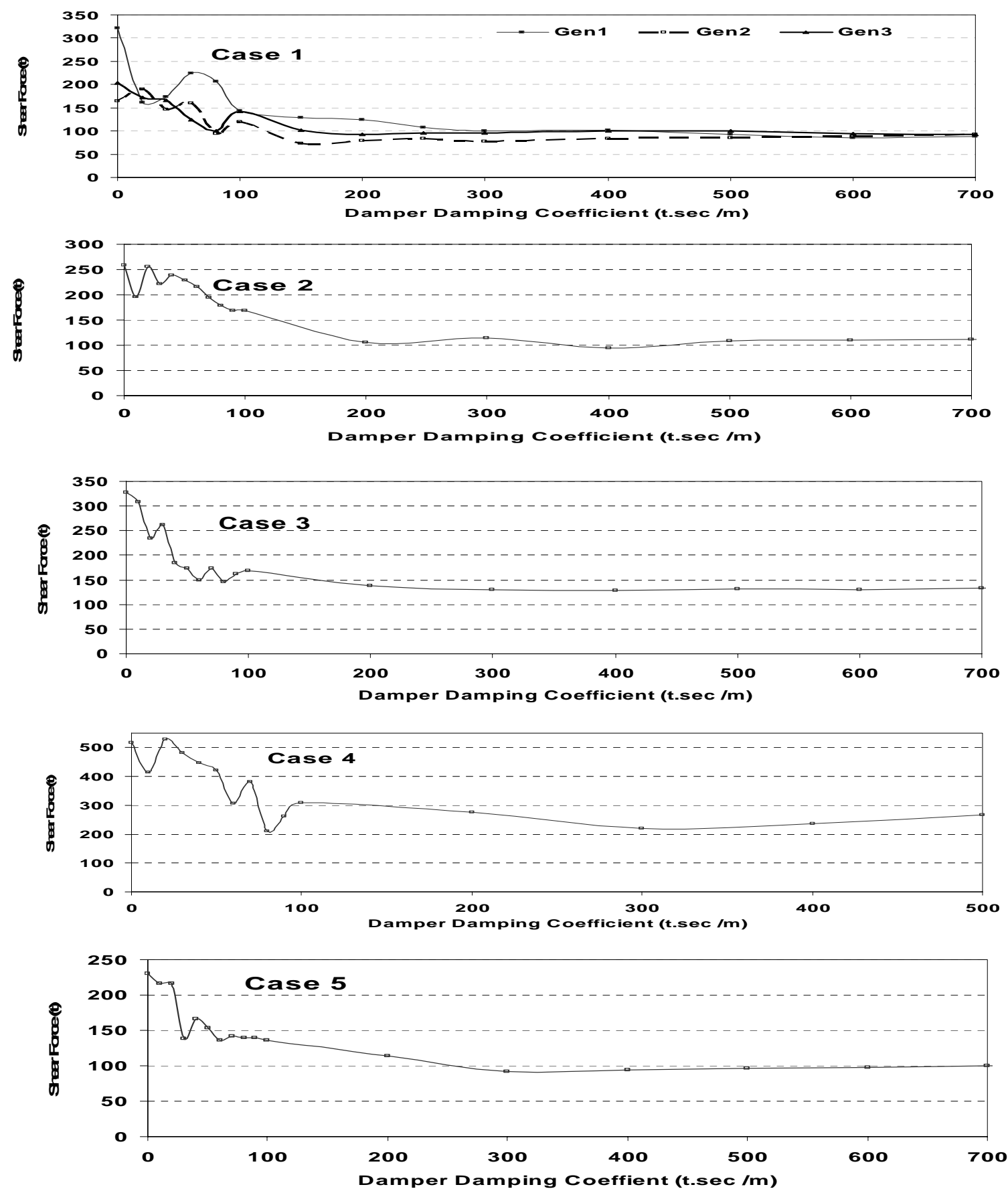

Fig. 10 : Relation between shear force F4 and different damping coefficients for different cases 